\title{
Densidade radicular de progênies de pupunheira em função de adubação NPK .
}

\author{
Marilene L. A. Bovi; Sandra H. Spiering; Antonia Marlene M. Barbosa \\ Instituto Agronômico, C. Postal 28, 13.001-970 Campinas - SP
}

\section{RESUMO}

$\mathrm{O}$ uso eficiente de fertilizantes requer o conhecimento de seus efeitos tanto na biomassa aérea quanto na radicular, permitindo que se identifique uma adubação adequada do ponto de vista de uma melhor partição entre ambas. A massa de raízes secas por volume de solo vem sendo utilizada, principalmente em espécies perenes, como subsídio para estimativas de biomassa radicular. Com esse objetivo, foram estudados os efeitos da adubação NPK na densidade radicular de três progênies de pupunheira (Bactris gasipaes Kunth), cultivadas em um Aluvial álico (corrigido por meio de calagem) em Ubatuba, SP (clima "Cfa"), durante o ano de 1993. O delineamento foi um fatorial fracionado, composto por quatro doses crescentes de nitrogênio (0 a $400 \mathrm{~kg} / \mathrm{ha} / \mathrm{ano}$ de $\mathrm{N})$, fósforo $(0$ a $200 \mathrm{~kg} / \mathrm{ha} / \mathrm{ano}$ de $\mathrm{P}_{2} \mathrm{O}_{5}$ ) e potássio $\left(0\right.$ a $200 \mathrm{~kg} / \mathrm{ha} / \mathrm{ano}$ de $\left.\mathrm{K}_{2} \mathrm{O}\right)$, em experimento integrado (progênies e adubação). As amostras foram coletadas por ocasião da primeira colheita de palmito (outubro de 1993), quando as plantas (cultivadas no espaçamento de $2 \times 1 \mathrm{~m}$ ) tinham cerca de dois anos de campo. Utilizou-se o método do trado, coletando-se, por parcela experimental, duas amostras na linha e duas na entrelinha. Houve diferenças entre genótipos (GE), com as progênies 2 e 3 apresentando, em média, maior densidade radicular que a progênie 1 (5,15 e 6,20 contra $2,61 \mathrm{~g} / \mathrm{dm}^{3}$, respectivamente). A interação GE x PO (posição da amostra) foi significativa, sendo que para as progênies 1 e 2 a maior densidade radicular foi obtida na linha $(3,30$ e $6,60 \mathrm{~g} / \mathrm{dm}^{3}$ na linha, contra 1,92 e $4,70 \mathrm{~g} / \mathrm{dm}^{3}$ na entrelinha, respectivamente), enquanto para a 3 a ordem foi inversa $\left(5,57 \mathrm{~g} / \mathrm{dm}^{3}\right.$ na linha e $6,84 \mathrm{~g} / \mathrm{dm}^{3}$ na entrelinha). Doses crescentes de potássio $(\mathrm{K})$ apresentaram efeitos lineares positivos e significativos $\left(\mathrm{R}^{2}=0,93\right.$ a $0,97)$ na densidade radicular das três progênies, com acréscimos entre dose mínima e máxima variando de 18 a $28 \%$. Não houve efeito significativo isolado de $\mathrm{P}$, enquanto doses crescentes de $\mathrm{N}$ proporcionaram um efeito linear positivo e significativo, mais evidente na progênie 1 (médias de 2,26, 2,39, 2,62 e 3,16 g/ $/ \mathrm{dm}^{3}$ para as doses 0 , 100,200 e $400 \mathrm{~kg} / \mathrm{ha} /$ ano de $\mathrm{N}$, respectivamente). Não houve interação estatisticamente significativa entre GE e fertilizantes aplicados (NPK), exceto para GE x N x P. Embora com respostas diferenciais de acordo com a progênie, constatou-se que a maior densidade radicular foi sempre obtida nas doses mais elevadas de $\mathrm{N}$.

Palavras-chave: Bactris gasipaes, sistema radicular, palmito, absorção de nutrientes.

\author{
ABSTRACT \\ Root density of pejibaye progenies as a function of NPK \\ fertilization.
}

The efficient use of fertilizers requires a knowledge of their effects, not only on shoot biomass, but also on below-ground biomass, to identify an adequate fertilization level from the point of view of a better partition between both. Dried root mass per soil volume has been used, especially in perennial crops, as a substitute for estimates of root biomass. With this objective, the root density of three progenies of the pejibaye palm (Bactris gasipaes Kunth) was studied under a combination of four nitrogen (0 to $400 \mathrm{~kg} / \mathrm{ha} /$ year of $\mathrm{N})$, phosphorus ( 0 to $200 \mathrm{~kg} / \mathrm{ha} /$ year of $\mathrm{P}_{2} \mathrm{O}_{5}$ ) and potassium ( 0 to 200 $\mathrm{kg} / \mathrm{ha} /$ year of $\mathrm{K}_{2} \mathrm{O}$ ) doses, in a field experiment. The area was located at Ubatuba, SP, Brazil, in an allic alluvial soil, corrected by liming. The samples were collected during the first heart of palm harvest (October, 1993), when the plants (cultivated in a 2 x $1 \mathrm{~m}$ spacing) were two years old. Samples were collected, between and within planting rows, using a root-soil auger sampler, $50 \mathrm{~cm}$ from the main stem and at a 0-20 cm soil depth. There were differences among genotypes (GE), with progenies 2 and 3 showing, on average, higher root densities than progeny $1\left(5.15\right.$ and 6.20 , against $2.61 \mathrm{~g} / \mathrm{dm}^{3}$, respectively). The interaction GE x PO (sample position) was significant: progenies 1 and 2 showed the highest root densities within planting rows $\left(3.30\right.$ and $6.60 \mathrm{~g} / \mathrm{dm}^{3}$ within row, against 1.92 and $4.70 \mathrm{~g} / \mathrm{dm}^{3}$ between rows, respectively), while progeny 3 showed an inverse order $\left(5.57 \mathrm{~g} / \mathrm{dm}^{3}\right.$ in the within row, and $6.84 \mathrm{~g} / \mathrm{dm}^{3}$ between rows). There was a positive linear response to applied potassium $\left(\mathrm{R}^{2}\right.$ $=0.93$ to 0.97 ), with increments between minimum and maximum doses varying from 18 to $28 \%$. There was no isolated significant effect of $\mathrm{P}$, while increasing doses of $\mathrm{N}$ provided a positive and significant linear effect, more evident in progeny 1 (averages of 2.26, $2.39,2.62$ and $3.16 \mathrm{~g} / \mathrm{dm}^{3}$ for the doses $0,100,200$ and $400 \mathrm{~kg} / \mathrm{ha} /$ year of $\mathrm{N}$, respectively). There was no significant interaction between GE and fertilizers (NPK), except for GE x N x P. Although the responses varied with progeny, higher root density was always found at high nitrogen doses.

Keywords: Bactris gasipaes, root-system, heart of palm, nutrient uptake.

\section{(Aceito para publicação em 01 de outubro de 1999)}

$\mathrm{P}^{\mathrm{a}}$ almeiras apresentam uma alta demanda por nutrientes para maximizar crescimento e produção (Hartley, 1977; Tinker, 1982; Bovi \& Cantarella, 1996). No entanto, a magnitude das respostas à aplicação de fertilizantes depende de uma série de fatores relacionados à aquisição, transporte e utilização dos nutrientes disponíveis e aplicados ao solo. O sistema radicular das plantas ocupa não mais que $2 \%$ do volume superficial do solo (Böhm, 1979; Sieverding, 1991). Portanto, as relações entre a biomassa radicular e a quantidade e a proporção dos nutrientes aplicados determinam a eficiência de absorção e, consequentemente, as respostas de crescimento e/ou produção (Mengel, 1983). Comparadas às dicotiledôneas, palmeiras possuem sistema radicular pouco eficiente devido à presença em grande proporção de raízes grossas, fibrosas e sem pelos absorventes (Tomlinson, 1990). Talvez por isso, 
alocam proporcionalmente mais biomassa às raízes do que as dicotiledôneas. A absorção de nutrientes nessas plantas tende a ser função quase que exclusiva do desenvolvimento do sistema radicular.

O uso de fertilizantes em cultivos com alta extração de nutrientes exige cautela. O suprimento inadequado de nutrientes, tanto falta quanto excesso, pode provocar restrições ao crescimento das plantas e alterar relações entre biomassa aérea e radicular. Desbalanceamentos entre crescimento radicular e aéreo, causados por falta ou excesso de algum nutriente, são reportados em algumas espécies (Buwalda \& Goh, 1982; Peng et al., 1993), evidenciando que nem sempre a alocação de maior quantidade de fotossintatos ao sistema radicular se traduz em maior crescimento da parte aérea. Em plantas dependentes de fungos micorrízicos, como a pupunheira (Sudo et al., 1996), esse efeito pode ser ainda maior, com uma mudança no comportamento simbiótico entre micorrizas e planta hospedeira. Embora a associação entre fungos micorrízicos e plantas tenha se mostrado benéfica em situações de baixa disponibilidade de fósforo (Chulan, 1991), ela é altamente detrimental em condições de elevada disponibilidade desse elemento (Peng et al., 1993). Há, nessas condições, maior demanda do fungo por fotossintatos, induzindo a planta a aumentar o sistema radicular em detrimento do crescimento da biomassa aérea. Sabe-se que a produção de palmito por pupunheiras e a duração econômica do cultivo estão direta e positivamente associadas à sua biomassa aérea (Mora-Urpí et al., 1997; Bovi, 1998). Dessa forma, fatores que possam interferir nessa característica devem ser objeto de pesquisa.

O crescimento e a densidade radicular são bastante afetados pelas propriedades físicas e químicas do solo (Barley, 1970). Segundo esse autor, a fertilidade de um solo reside, pelo menos parcialmente, na habilidade das raízes crescerem e se ramificarem facilmente no mesmo. Poucos são os artigos que relatam os efeitos da adubação no crescimento ou densidade radicular a campo (Anilkumar \& Wahid, 1988;
Pavan, 1995). A dificuldade da análise da biomassa radicular nessas condições provavelmente é um dos principais fatores que restringem esses estudos.

Existem vários métodos para o estudo do sistema radicular de cultivos. Dentre eles, o método do trado descrito por Böhm (1979), além da simplicidade, mostra-se bastante adequado quando grande parte do sistema radicular está nas primeiras camadas de solo. Por esse motivo, o método é indicado para plantas com sistema radicular fasciculado. Embora possa subestimar a densidade de raízes, devido a perdas no processo de lavagem das mesmas, o método é apropriado para avaliações comparativas de tratamentos. $\mathrm{O}$ modo de reportar a quantidade de raízes presentes em uma amostra também tem sido sujeito a muitas indagações. Comprimento, diâmetro e porcentagem de raízes em diferentes categorias de tamanho têm sido reportados (Gardner, 1960; Tailliez, 1971; Farrell et al., 1993). No entanto, quando é feita comparação entre tratamentos, a densidade radicular, expressa em massa/volume ou em comprimento/volume, é uma das características mais utilizadas (Gross et al., 1992; Hauser, 1993; Mullins et al., 1994).

Existe alguma informação sobre o sistema radicular da pupunheira. Artigos de Vandermeer (1977), Ferreira et al. $(1980 ; 1995)$ e Morales \& Vargas (1990) relatam que essa espécie possui raízes em sistema fasciculado, com cerca de 75 a $80 \%$ delas distribuídas, de modo mais ou menos uniforme, nos primeiros $20 \mathrm{~cm}$ do solo. Algumas raízes apresentam maiores diâmetros, são mais curtas e possuem acentuado geotropismo, sendo consideradas raízes de sustentação ou ancoramento. Há ainda alguma informação sobre o comportamento do sistema radicular da pupunheira em solos distintos (Ferreira et al., 1980; 1995). Em ambos os estudos, foram utilizadas plantas adultas (cerca de 13 e 17 anos de idade, respectivamente), não submetidas a adubações regulares. No entanto, artigos comparando densidade radicular de pupunheiras cultivadas para a produção de palmito, tanto em solos distintos como sob diferentes condições de fertilização, não foram encontrados na literatura.
O presente trabalho foi realizado visando estudar os efeitos da adubação NPK em um Aluvial álico na densidade radicular de pupunheiras, de forma a relacioná-la posteriormente com teores de elementos no solo, crescimento da planta e taxa de colonização de raízes por fungos micorrízicos nativos, permitindo que se identifique uma adubação adequada do ponto de vista de uma melhor partição entre biomassa aérea e biomassa radicular.

\section{MATERIAL E MÉTODOS}

Foram utilizadas parcelas experimentais de um ensaio fatorial fracionado instalado na Estação Experimental do Instituto Agronômico, localizada em Ubatuba $\left(23^{\circ} 27^{\prime} \mathrm{S}, 4^{\circ} 04^{\prime} \mathrm{W}\right.$, a seis metros de altitude). O clima da região é "Cfa", pela classificação de Köppen, tropical, quente e úmido, com pluviosidade anual normal de $2841 \mathrm{~mm}$, evapotranspiração potencial normal de $992 \mathrm{~mm}$, excedente normal de $1849 \mathrm{~mm}$, temperatura média anual de $20,8^{\circ} \mathrm{C}$ e déficit hídrico nulo. Os tratamentos foram quatro doses de nitrogênio $(0,100$, 200 e $400 \mathrm{~kg}$ de $\mathrm{N} / \mathrm{ha}$ ), de fósforo ( 0 , 50,100 e $200 \mathrm{~kg}$ de $\left.\mathrm{P}_{2} \mathrm{O}_{5} / \mathrm{ha}\right)$ e de potássio $(0,50,100$ e $200 \mathrm{~kg}$ de $\mathrm{K}, \mathrm{O} / \mathrm{ha})$, divididas em cinco aplicações anuais ao longo da estação chuvosa (outubro a março). As fontes de nutrientes foram, respectivamente, nitrocálcio $(22 \%$ de $\mathrm{N})$, superfosfato triplo $\left(45 \%\right.$ de $\left.\mathrm{P}_{2} \mathrm{O}_{5}\right)$ e cloreto de potássio $(60 \%$ de $\mathrm{K} \mathrm{O})$. Os adubos foram aplicados em cobertura, em faixas de $50 \mathrm{~cm}$ de largura, dos dois lados das plantas. A adubação teve início seis meses após a instalação do experimento.

O ensaio foi conduzido em solo classificado como Aluvial álico (Udifluvent), com as seguintes propriedades químicas a 0-20 cm de profundidade, após aplicação de calcário dolomítico visando elevar a saturação por bases (originalmente 14\%) e diminuir a saturação em alumínio: $\mathrm{pH}$ em $\mathrm{CaCl}_{2}$ 5,0 (equivalente a $\mathrm{pH}$ 5,6 em água); matéria orgânica $39 \mathrm{~g} / \mathrm{dm}^{3}$; $\mathrm{P}$ (resina) $9 \mathrm{mg} / \mathrm{dm}^{3}$; K 1,3; Ca 28; Mg 16; $\mathrm{H}+\mathrm{Al} 43 \mathrm{mmol}_{\mathrm{c}} / \mathrm{dm}^{3}$; capacidade de troca catiônica $88 \mathrm{mmol} / \mathrm{dm}^{3}$; saturação por alumínio de $0 \%$ e saturação por ba- 
ses de $51 \%$. O relevo da área experimental é plano, apresenta boa drenagem e não há erosão. A composição granulométrica do solo na profundidade de $0-15 \mathrm{~cm}$ é de $10 \%$ de argila, $14 \%$ de silte, $13 \%$ de areia fina e $63 \%$ de areia grossa. A maiores profundidades há uma progressiva diminuição na porcentagem de areia grossa e aumento de areia fina. A porosidade total na profundidade de 0-20 cm é de 49,97\%, sendo constituída por $29,65 \%$ de macroporos e $20,32 \%$ de microporos. Na camada imediatamente inferior (20-40 cm) há uma redução acentuada da microporosidade $(9,75 \%)$ e um aumento da macroporosidade $(42,92 \%)$. A densidade global nas duas camadas está em torno de $1,20 \mathrm{~g} / \mathrm{cm}^{3}$ (Jorge \& Bovi, 1994).

O espaçamento entre plantas foi de $2 \times 1 \mathrm{~m}$. As parcelas possuíam 24 plantas úteis, com bordaduras duplas ao redor e as progênies, da raça "microcarpa" Pará (Mora-Urpí \& Clement, 1988), estavam sorteadas dentro de cada parcela. Para o presente estudo foram utilizadas três progênies. Dentro de cada progênie, as amostragens para o cálculo da densidade radicular foram feitas com duas repetições na linha e duas na entrelinha. As plantas apresentavam, por ocasião da amostragem, dois anos de campo e não tinham sido ainda colhidas. Cerca de $70 \%$ das plantas no experimento estavam aptas à colheita.

Observações preliminares sobre a distribuição do sistema radicular das plantas sob essas condições de cultivo foram feitas em duas plantas localizadas nas bordas do ensaio. Utilizou-se o método de trincheira (Böhm, 1979), com profundidade até $2 \mathrm{~m}$ e distância do estipe principal de $3 \mathrm{~m}$. A partir dessas observações preliminares, assumindo-se simetria radial, estabeleceu-se que a maior concentração de raízes na profundidade de 0 a $20 \mathrm{~cm}$ estava a uma distância de $50 \mathrm{~cm}$ do estipe.

A densidade radicular das touceiras dos diferentes tratamentos (combinações de doses de NPK) foi estimada pelo método do trado (Böhm, 1979), segundo metodologia descrita por Fujiwara $e t$ al. (1994). Retiraram-se amostras na linha ( $1 \mathrm{~m}$ entre plantas) e na entrelinha ( $2 \mathrm{~m}$ entre plantas) para cada ponto amostrado, ambas a cerca de $50 \mathrm{~cm}$ da planta e na profundidade de 0 a $20 \mathrm{~cm}$, onde, segundo a literatura (Vandermeer, 1977; Ferreira et al., 1980; 1995; Morales \& Vargas, 1990) e as observações preliminares, mais de $80 \%$ das raízes da pupunheira se situam. As raízes foram separadas do solo, lavadas e pesadas. A secagem das mesmas foi feita em estufa a $70^{\circ} \mathrm{C}$ até peso constante, seguindo-se nova pesagem. Os dados foram expressos em massa de raízes secas por volume de solo $\left(\mathrm{g} / \mathrm{dm}^{3}\right)$.

Os resultados foram submetidos à análise de variância, com comparação entre médias feita pelo teste de Tukey a $5 \%$. Regressões múltiplas em passos foram usadas para modelar a resposta das doses crescentes dos elementos na densidade radicular das progênies de pupunheira. A escolha da equação que melhor se ajustou aos dados foi baseada na significância do efeito da regressão, dos desvios da regressão testados pelo teste $\mathrm{F}$ a $5 \%$ de probabilidade e no maior coeficiente de determinação $\left(\mathrm{R}^{2}\right)$. Os coeficientes das equações de regressão foram testados até $10 \%$ pelo teste " $\mathrm{t}$ ". As derivadas primeiras das equações foram igualadas a zero, determinando-se as doses dos elementos associadas à máxima e à mínima densidade radicular por genótipo.

\section{RESULTADOS E DISCUSSÃO}

\section{Caracterização e dimensões das raízes}

O sistema radicular das plantas observado pelo método de trincheira, seguiu, de um modo geral, o padrão apresentado pelas palmeiras (Tailliez, 1971; Hartley, 1977; Avilan et al., 1984; Tomlinson, 1990). Mostrou-se como do tipo fasciculado, com a grande maioria das raízes de primeira ordem ou primárias (R1) crescendo horizontalmente e medindo cerca de 3,3 a 5,9 mm de diâmetro. A maior parte delas alcançou, nas plantas observadas, de 1,5 a 2,0 m na horizontal. Algumas raízes primárias cresciam verticalmente, alcançando profundidades em torno de 1,5 a $2 \mathrm{~m}$, sendo consideradas raízes de sustentação. No entanto, notou-se que o ancoramento dessas plantas não é bom. Tombamento de touceiras após ocorrência de ventos fortes tem sido frequentemente obser- vado no banco de germoplasma dessas palmeiras instalado na região.

Observou-se que as raízes de segunda ordem ou secundárias (R2) originaram-se de ramificações das raízes primárias, apresentando dimensões de 1,2 a 2,9 mm de diâmetro, chegando a alcançar até $35 \mathrm{~cm}$ de comprimento. Podem ter crescimento ascendente ou descendente, com uma tendência das raízes superficiais crescerem acima da superfície do solo. Raízes terciárias (R3) saíram das secundárias e apresentaram dimensões em torno de 0,4 a $1,1 \mathrm{~mm}$ de diâmetro e 2 a $8 \mathrm{~cm}$ de comprimento. As raízes quaternárias ( $\mathrm{R} 4)$ raramente mediram mais do que $2 \mathrm{~cm}$, com maior frequência encontrada entre 0,1 a $1 \mathrm{~cm}$ de comprimento e diâmetros sempre inferiores a 0,5 mm (média entre 0,16 a $0,32 \mathrm{~mm}$ ). Juntamente com as terciárias, essas raízes são consideradas os órgãos principais de absorção em palmeiras e podem ser extensivamente desenvolvidas em solos ricos em nutrientes e matéria orgânica (Tomlinson, 1990). Como nas demais palmeiras, observou-se que as raízes de pupunheira não possuem pelos absorventes. No entanto, presume-se que a absorção é facilitada pelo grande número de raízes, alta proporção de raízes secundárias e terciárias em relação às de maiores diâmetros e presença de fungos micorrízicos que comportam-se como prolongamentos do sistema radicular (Tomlinson, 1990; Sieverding, 1991).

Observou-se ainda que as raízes saíram invariavelmente em ângulo próximo a $90^{\circ}$. Houve variação nesse padrão apenas quando as raízes foram anterior e involuntariamente cortadas, o que pode ocorrer durante a operação de roçada. Nesse caso, detectou-se um crescimento em tufo das raízes (observouse de quatro a oito raízes de diâmetros apenas um pouco inferiores à secção cortada), principalmente das R1 e R2, que ocorreu próximo ao ponto de corte.

Embora não tenha sido feita separação das raízes por diâmetro em cada amostra dos tratamentos analisados (parcelas com diferentes combinações de NPK), observou-se que o diâmetro médio das raízes teve variação semelhante às duas plantas anteriormente observadas (5,9 a 0,16 mm). Observouse ainda que cerca de $63 \%$ (em peso) 
dos segmentos de raízes amostradas pertenciam às classes de menores diâmetros (raízes terciárias e quaternárias - 1,1 a $0,16 \mathrm{~mm}$ ), sem variações nítidas nessa porcentagem entre os tratamentos. Dimensões próximas às aqui encontradas foram obtidas anteriormente por Ferreira et al. (1995).

\section{Efeito de genótipos}

Observou-se, pela análise de variância dos dados obtidos pelo método do trado, influência significativa dos genótipos $(\mathrm{F}=82,92 * * *)$ na densidade radicular da pupunheira. Não ocorreram interações significativas entre genótipos e nutrientes isolados ( $\mathrm{F}$ de $\mathrm{GE} \times \mathrm{N}=$ 0,91ns; F de GE x P = 1,07ns; F de GE $\mathrm{x} K=0,92 \mathrm{~ns}$ ). Não foram também significativas as interações triplas entre genótipo, nitrogênio e potássio ( $\mathrm{F}$ de $\mathrm{GE}$ x $\mathrm{N} \times \mathrm{K}=0,87 \mathrm{~ns}$ ) e entre genótipos, fósforo e potássio ( $\mathrm{F}$ de $\mathrm{GE} \times \mathrm{P} \times \mathrm{K}=$ 0,73ns). Apenas a interação entre genótipos, nitrogênio e fósforo mostrou ser significativa a $1 \%$ de probabilidade (F de GE x $\mathrm{N} \times \mathrm{P}=3,14^{*}$ ). Pela significância dessa interação para palmeiras, a mesma será discutida mais adiante. Por sua vez, a interação entre genótipos e posição das amostras foi significativa ( $\mathrm{F}$ de $\mathrm{GE} \times \mathrm{PO}=15,12 * * *)$ indicando que as progênies divergem na densidade radicular encontrada na linha e na entrelinha. A progênie 1 apresentou significativamente menor densidade radicular que as progênies 2 e 3 (Tabela 1), tanto na linha como na entrelinha. Dois fatores principais podem estar envolvidos. O primeiro deles referese ao fato, já constatado para várias espécies vegetais (Salisbury \& Ross, 1991), de que genótipos divergem na partição entre biomassa aérea e biomassa radicular. Raízes, assim como folhas e frutos, são drenos (centros de importação de fotoassimilados). No entanto, são drenos mais fracos que esses dois últimos órgãos. Sempre que houver uma maior demanda de crescimento e expansão da parte aérea, estabelece-se um processo competitivo entre drenos que resulta no esgotamento das reservas das raízes e na paralisação de seu crescimento, em detrimento de maior crescimento aéreo (Salisbury \& Ross, 1991). Diferenças entre material genético para biomassa aérea e radicular têm sido reportadas em outras palmeiras (Ruer, 1967a,b; Hardon, 1982).

Outro fator que poderia ser aventado como causa da diferenças significativa para densidade radicular entre progênies está relacionado à maior ou menor suscetibilidade de genótipos ao alumínio. Tratando-se de solo originalmente ácido, tal fator poderia estar envolvi-

Tabela 1. Densidade radicular média de progênies de pupunheiras quando cultivadas sob doses crescentes de adubação nitrogenada, fosfatada e potássica. Ubatuba, Instituto Agronômico, 1998.

\begin{tabular}{|c|c|c|c|c|c|c|c|}
\hline Elementos e doses & Progênie 1 & Progênie 2 & Progênie 3 & Progênie 1 & Progênie 2 & Progênie 3 & Médias \\
\hline & & Linha & & & Entrelinha & & \\
\hline & & & & $\mathrm{g} / \mathrm{dm} 3$ & & & \\
\hline \multicolumn{8}{|l|}{ Nitrogênio } \\
\hline 0 & $2,53 \mathrm{~B} \mathrm{a}$ & $5,28 \mathrm{~A} \mathrm{a}$ & $5,82 \mathrm{~A} \mathrm{~b}$ & $1,98 \mathrm{C} \mathrm{b}$ & $5,62 \mathrm{~B}$ a & $7,69 \mathrm{~A} \mathrm{a}$ & 4,82 \\
\hline 100 & $3,24 \mathrm{Ca}$ & $5,54 \mathrm{~A} \mathrm{a}$ & $4,84 \mathrm{~B} \mathrm{~b}$ & $1,55 \mathrm{C} \mathrm{b}$ & $3,71 \mathrm{~B} \mathrm{~b}$ & $5,75 \mathrm{~A} \mathrm{a}$ & 4,11 \\
\hline 200 & $3,53 \mathrm{~B} \mathrm{a}$ & $5,56 \mathrm{~A} a$ & $5,25 \mathrm{~A} \mathrm{~b}$ & $1,71 \mathrm{C} \mathrm{b}$ & $4,41 \mathrm{~B} \mathrm{~b}$ & $7,23 \mathrm{~A} \mathrm{a}$ & 4,62 \\
\hline 400 & $3,90 \mathrm{~B} \mathrm{a}$ & $6,02 \mathrm{~A} \mathrm{a}$ & $6,35 \mathrm{~A} a$ & $2,42 \mathrm{Cb}$ & $5,08 \mathrm{~B} \mathrm{~b}$ & $6,67 \mathrm{~A} \mathrm{a}$ & 5,07 \\
\hline \multicolumn{8}{|l|}{ Fósforo } \\
\hline 0 & $3,61 \mathrm{~B}$ a & $5,50 \mathrm{~A} a$ & $5,01 \mathrm{~A} \mathrm{~b}$ & $1,99 \mathrm{C} \mathrm{b}$ & $4,46 \mathrm{~B} \mathrm{~b}$ & $6,81 \mathrm{~A} \mathrm{a}$ & 4,56 \\
\hline 50 & $2,45 \mathrm{C} \mathrm{a}$ & $5,58 \mathrm{~B} \mathrm{a}$ & $6,43 \mathrm{~A} a$ & $1,73 \mathrm{C} \mathrm{b}$ & $4,99 \mathrm{~B} \mathrm{~b}$ & $6,65 \mathrm{~A} \mathrm{a}$ & 4,64 \\
\hline 100 & $3,43 \mathrm{~B} \mathrm{a}$ & $5,55 \mathrm{~A} \mathrm{a}$ & $5,65 \mathrm{~A} \mathrm{~b}$ & $2,01 \mathrm{C} \mathrm{b}$ & $4,64 \mathrm{~B} \mathrm{~b}$ & $7,73 \mathrm{~A} \mathrm{a}$ & 4,80 \\
\hline 200 & $3,73 \mathrm{~B} \mathrm{a}$ & $5,77 \mathrm{~A} a$ & $5,19 \mathrm{~A} \mathrm{~b}$ & $1,93 \mathrm{C} \mathrm{b}$ & $4,72 \mathrm{~B} \mathrm{~b}$ & $6,35 \mathrm{~A} \mathrm{~b}$ & 4,61 \\
\hline \multicolumn{8}{|l|}{ Potássio } \\
\hline 0 & $2,96 \mathrm{~B} \mathrm{a}$ & $5,27 \mathrm{~A} \mathrm{a}$ & $5,29 \mathrm{~A} \mathrm{~b}$ & $1,89 \mathrm{Cb}$ & $3,97 \mathrm{~B} \mathrm{~b}$ & $6,10 \mathrm{~A} \mathrm{a}$ & 4,24 \\
\hline 50 & $3,05 \mathrm{C} \mathrm{a}$ & $4,75 \mathrm{~B}$ a & $5,22 \mathrm{~A} b$ & $1,82 \mathrm{C} \mathrm{b}$ & $4,51 \mathrm{~B} \mathrm{a}$ & $6,51 \mathrm{~A} \mathrm{a}$ & 4,31 \\
\hline 100 & $3,73 \mathrm{~B}$ a & $5,72 \mathrm{~A} a$ & $5,37 \mathrm{~A} b$ & $1,68 \mathrm{C} \mathrm{b}$ & $5,16 \mathrm{~B} \mathrm{~b}$ & $6,71 \mathrm{~A} \mathrm{a}$ & 4,73 \\
\hline 200 & $3,47 \mathrm{~B} \mathrm{a}$ & $6,66 \mathrm{~A} a$ & $6,40 \mathrm{~A} \mathrm{~b}$ & $2,27 \mathrm{C} \mathrm{b}$ & 5,17 B b & $8,03 \mathrm{~A} \mathrm{a}$ & 5,33 \\
\hline Médias & 3,30 & 6,60 & 5,57 & 1,92 & 4,70 & 6,84 & 4,48 \\
\hline CV (\%) & 50,50 & 29,72 & 22,09 & 46,12 & 27,14 & 26,09 & 34,83 \\
\hline
\end{tabular}

Médias seguidas da mesma letra na horizontal (maiúsculas para comparação entre progênies na mesma posição de amostra e minúsculas para comparação entre posições de amostra dentro da mesma progênie) não diferem entre si a 5\% de probabilidade pelo Teste de Tukey. 


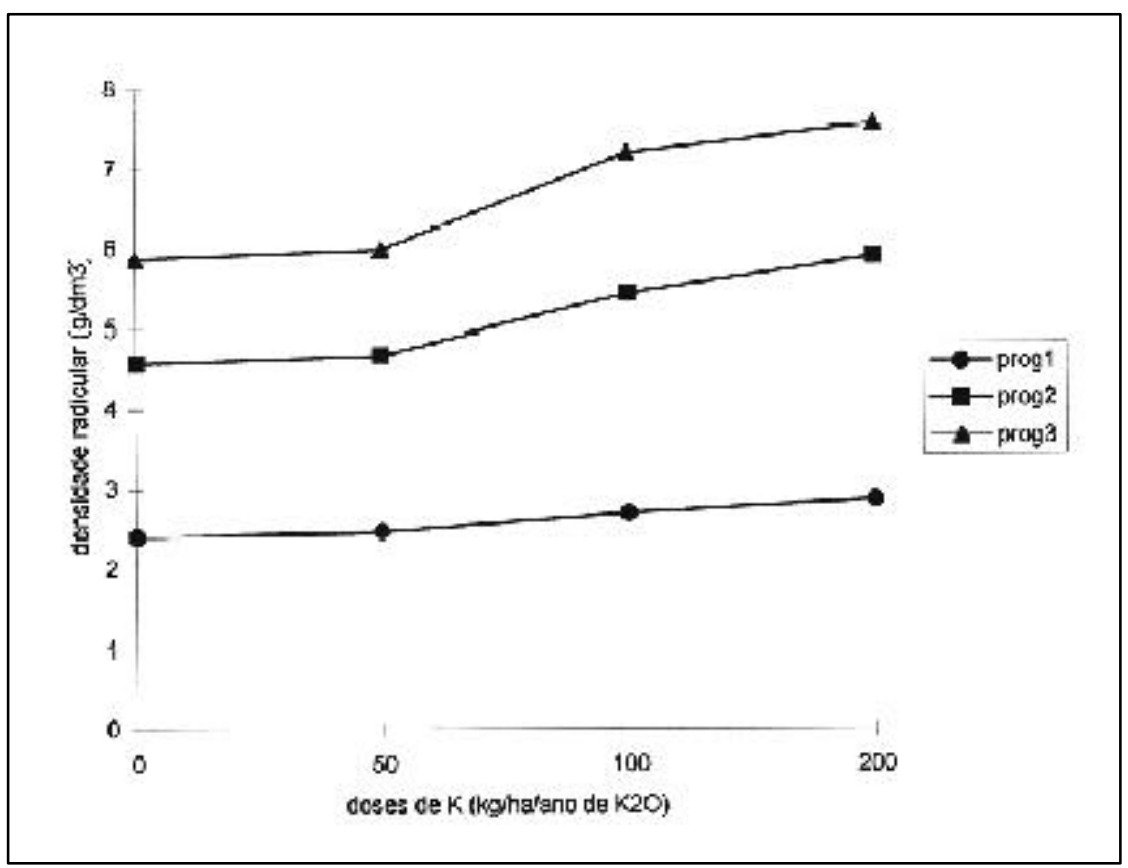

Figura 1. Densidade radicular de progênies de pupunheira em função de doses crescentes de potássio. Ubatuba, Instituto Agronômico, 1998.

do. No entanto o solo foi corrigido previamente com calcário, alcançando $\mathrm{pH}$ em água de 5,6, com consequente neutralização do alumínio trocável (saturação por alumínio $=0$ ). Além disto, as raízes do genótipo com menor densidade radicular apresentavam a mesma morfologia e medidas dos demais genótipos, não evidenciando os sintomas usuais de toxidez ao elemento e, deve-se lembrar ainda, que a pupunheira é uma espécie tropical, nativa de regiões com solos ácidos, de baixos teores de nutrientes e com elevada saturação por alumínio (Mora-Urpí, 1984), portanto originalmente pouco sensível à toxidez causada por esse elemento. Essa característica foi comprovada recentemente por Pachêco (1997) em mudas de pupunheira cultivadas em solução nutritiva com concentrações crescentes de $\mathrm{Al}$ ( 0 a $30 \mathrm{mg} / \mathrm{L}$ ). $\mathrm{O}$ autor reporta que não foram visualizados sintomas tais como encurtamento e engrossamento de raízes e que os maiores efeitos foram na parte aérea (redução no crescimento devido a menor absorção de $\mathrm{Ca}, \mathrm{Mg}$ e P) e não no sistema radicular, concluindo que, em relação a outras plantas cultivadas, a pupunheira mostrou ser tolerante ao alumínio.

\section{Posição das amostras}

Não houve efeito significativo da posição das amostras ( $\mathrm{F}=2,09 \mathrm{~ns})$ quan- do se considerou a média das progênies. No entanto, a interação progênie $\mathrm{x}$ posição das amostras (GE x PO) foi significativa (F 15,12***). Não obstante, não houve interações significativas (simples ou múltiplas) entre posição da amostra e nutrientes. Via de regra, maiores densidades radiculares na linha (média de 3,30 e $6,60 \mathrm{~g} / \mathrm{dm}^{3}$, respectivamente) foram obtidas para as progênies $1 \mathrm{e}$ 2 , enquanto para a progênie 3 , maiores massas radiculares por volume fixo de solo foram encontradas na entrelinha (média de 6,84 g/dm³) (Tabela 1). Exceções são a progênie 2 na dose zero de $\mathrm{N}$ e na dose 50 de $K$, onde não houve diferença estatística na densidade radicular entre linha e entrelinha; e a progênie 3, onde as doses 400 de $\mathrm{N}$ e 50 de $\mathrm{P}$ não mostraram diferenças significativas entre a densidade radicular obtida na linha e na entrelinha. Como o espaçamento nas entrelinhas foi o dobro do espaçamento na linha, os resultados encontrados para as progênies $1 \mathrm{e}$ 2 estão dentro do esperado. Por sua vez, os resultados obtidos para a progênie 3 indicam que trata-se provavelmente de material genético com sistema radicular mais abrangente, exigindo maior espaçamento entre plantas. Não obstante a diferença entre densidade radicular encontrada para as progênies em estu- do, não é possível fazer nenhuma afirmação quanto à superioridade desta ou daquela, visto que o balanço entre as biomassas aérea e radicular é que indica a eficiência de um genótipo.

\section{Efeito isolado de potássio}

Dentre os elementos em estudo, houve um efeito linear positivo das doses de potássio aplicadas ao solo sobre a densidade radicular $(\mathrm{F}=5,10 * *)$ (Figura 1). Não foram detectadas interações significativas entre esse elemento e os demais, bem como entre ele e genótipos ( $\mathrm{F}$ de $\mathrm{N}$ x $\mathrm{K}=1,81 \mathrm{~ns} ; \mathrm{F}$ de $\mathrm{P}$ x $\mathrm{K}=$ $1,31 \mathrm{~ns}$; F de GE x K = 0,92 ns). As progênies reagiram de forma linear a doses crescentes de potássio. $\mathrm{O}$ efeito foi mais evidente nas progênies 2 e 3, que apresentaram acréscimos na densidade radicular, entre dose mínima e máxima de potássio, de 28,1 e 26,7\%, respectivamente (Tabela 1). A progênie 1, com densidade radicular média significativamente menor que as demais, apresentou menor acréscimo entre doses de $\mathrm{K}$ $(18,6 \%)$. De acordo com Sieverding (1991), a absorção dos íons que são supridos às raízes pelo mecanismo de difusão, tais como fósforo e potássio, depende da densidade de raízes por volume do solo. Um sistema radicular bem desenvolvido, principalmente com relação às raízes de menores diâmetros, apresenta maior área superficial, favorecendo a absorção desses nutrientes. Embora para algumas espécies, tais como algodão, seja notório o efeito de aplicação de potássio na densidade radicular (Mullins et al., 1994), não foram encontradas citações relacionandoos em palmeiras. No entanto, sabe-se que as palmeiras apresentam alta demanda por potássio, estando a biomassa aérea e a produção diretamente relacionadas a uma fertilização adequada em N e K (Hartley, 1977; Tinker, 1982; Bonneau et al., 1993). Principalmente em solos arenosos, como o do presente estudo, o potássio tem sido considerado o principal elemento que afeta o crescimento e a produção do dendezeiro (Hartley, 1977; Tinker, 1982).

\section{Interação entre $\mathbf{N}$ e $\mathbf{P}$}

Embora tenha sido reportado que o fósforo é um dos elementos que mais afetam o sistema radicular de várias espécies (Sieverding, 1991), não foi de- 
tectado efeito isolado, estatisticamente significativo, de doses de fósforo na densidade radicular de pupunheiras (F de $0,26 \mathrm{~ns}$ ). Por sua vez, não obstante tenha sido observado efeito significativo de doses de $\mathrm{N}$ (efeito linear positivo) na característica avaliada $(\mathrm{F}=$ $\left.3,96^{* *}\right)$, detectou-se também interação significativa entre nitrogênio e fósforo $\left(\mathrm{F}=6,83^{* * *}\right)$ e, mais importante, entre progênies e esses dois elementos (GE $\mathrm{x}$ $\mathrm{N} \times \mathrm{P}$, com $\left.\mathrm{F}=3,14^{* *}\right)$. Como reportado anteriormente, não houve interação significativa (simples ou múltipla) entre a posição da amostra e os nutrientes, permitindo que se avalie o efeito dos nutrientes nos diferentes genótipos pela média de suas densidades radiculares (linha e entrelinha). As figuras 2, 3 e 4 mostram a variação média da densidade radicular de cada uma das progênies em relação as doses de N e P. Interação significativa $\mathrm{N}$ x $\mathrm{P}$ já havia sido detectada anteriormente para as características biomassa aérea e atividade in vivo da enzima fosfatase ácida em folhas de pupunheira (Bovi et al., 1998). Interação positiva entre nitrogênio e fósforo tem sido reportada também para outras palmeiras (Ollagnier \& Ochs, 1980; Tinker, 1982; Tampubolon et al., 1990; Bonneau et al., 1993). Em todas as citações, o efeito de $\mathrm{N}$ em $\mathrm{P}$ é maior do que $\mathrm{o}$ efeito de $\mathrm{P}$ em $\mathrm{N}$, tal como o reportado aqui. Embora com respostas diferenciadas de acordo com a progênie em estudo, nota-se que maior densidade radicular foi sempre obtida nas doses mais elevadas de $\mathrm{N}$ (figuras 2, 3 e 4). Diante dos resultados obtidos com coqueiro e dendezeiro, Bonneau et al. (1993) argumentam que uma boa nutrição nitrogenada aumenta automaticamente o teor de $\mathrm{P}$ nessas palmeiras, mas isso não elimina a necessidade de aplicação de adubos fosfatados. Do ponto de vista fisiológico, o sinergismo de absorção e assimilação existente entre $\mathrm{N}$ e P é facilmente explicado. Enquanto o nitrogênio é parte estrutural da molécula da clorofila, a taxa de fotossíntese é fortemente influenciada pela concentração de fósforo inorgânico no cloroplasto (Salisbury \& Ross, 1991). Dessa forma, plantas bem nutridas em $\mathrm{N}$ e $\mathrm{P}$ têm maior capacidade de assimilação de $\mathrm{CO}_{2}$ e de sintetização de carboidratos durante a fotossíntese, re-

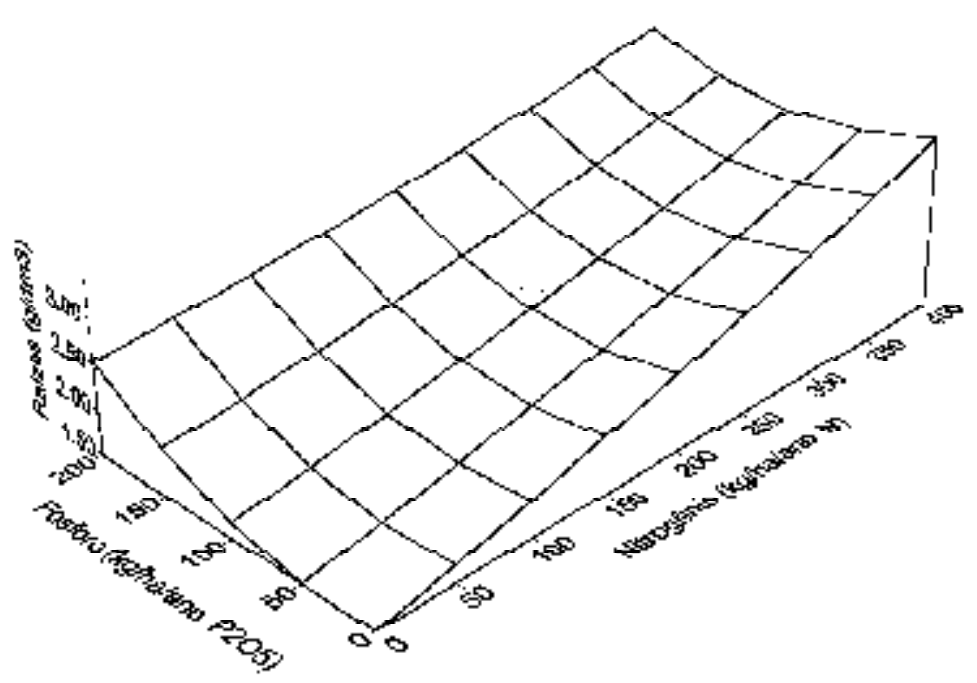

Figura 2. Densidade radicular da progênie 1 em função de doses de nitrogênio $(\mathrm{N})$ e fósforo (P) $(\mathrm{K}=0)$. Ubatuba, Instituto Agronômico, 1998.

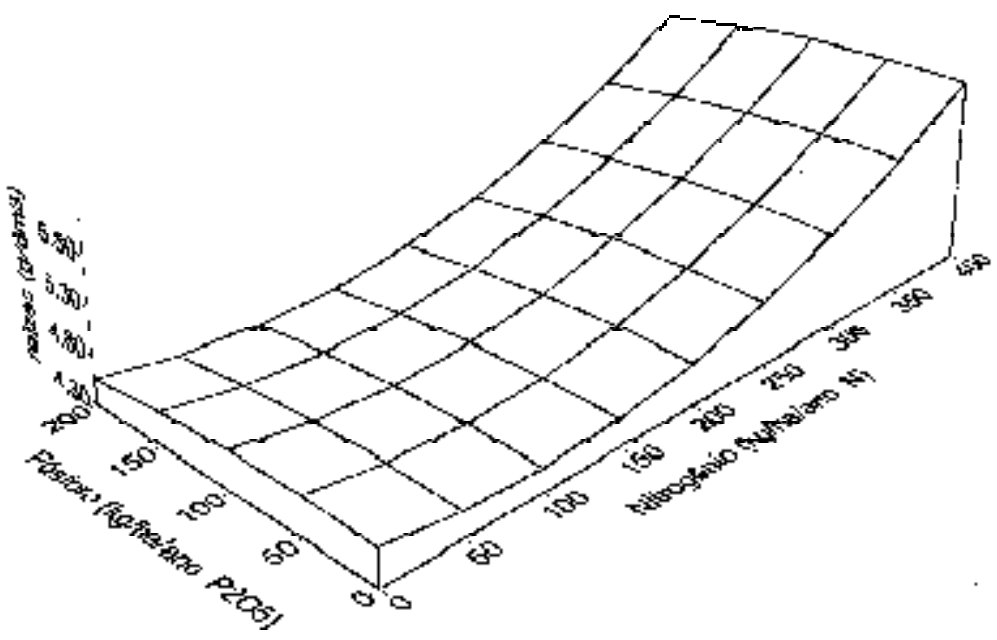

Figura 3. Densidade radicular da progênie 2 em função de doses de nitrogênio (N) e fósforo (P) $(\mathrm{K}=200)$. Ubatuba, Instituto Agronômico, 1998.

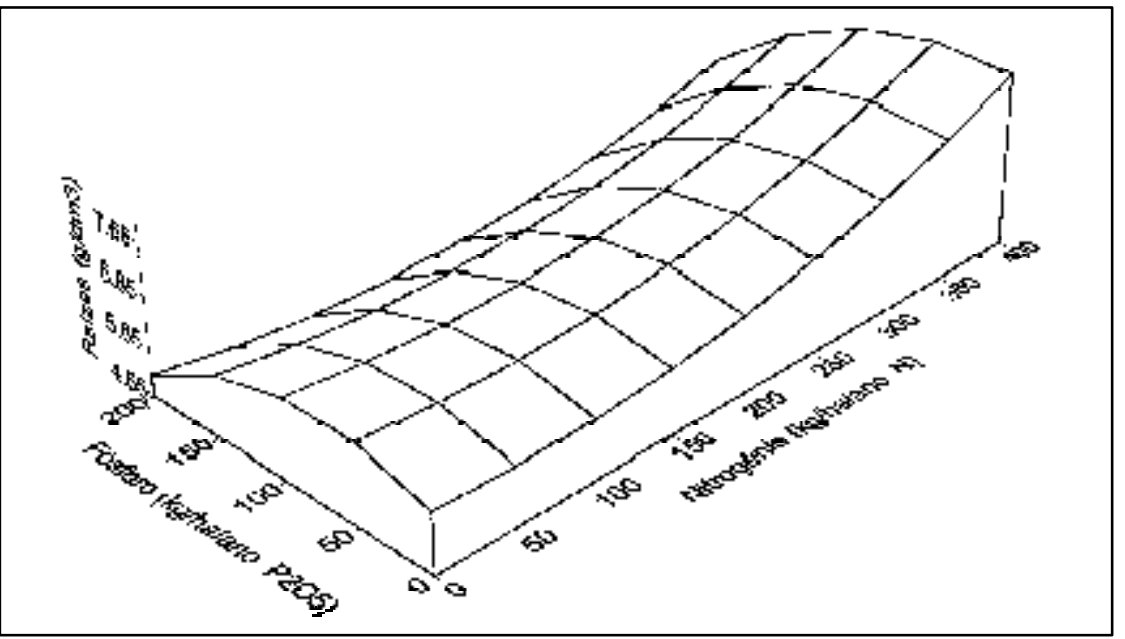

Figura 4. Densidade radicular da progênie 3 em função de doses de nitrogênio e fósforo (P) (K= 200). Ubatuba, Instituto Agronômico, 1998. 
sultando em maiores quantidades de biomassa. A maior alocação desta para o sistema radicular pode ser particularmente importante para a planta, pois permite mudanças na rizosfera (mediada pela exudação de ácidos orgânicos e interação com fungos micorrízicos), com consequiente aumento na aquisição de nutrientes minerais e água.

\section{Maximização e minimização das respostas}

As respostas modeladas por meio de análise de regressão, utilizando uma função polinomial quadrática, indicaram que as doses que maximizaram ou minimizaram a densidade radicular foram diferentes para cada uma das três progênies. Para a progênie 1 , a densidade radicular máxima $\left(3,4 \mathrm{~g} / \mathrm{dm}^{3}\right)$ foi obtida com a seguinte combinação de elementos: $\mathrm{N}=400 \mathrm{~kg} / \mathrm{ha} /$ ano de $\mathrm{N}, \mathrm{P}=0$ a 200 $\mathrm{kg} / \mathrm{ha} /$ ano de $\mathrm{P}_{2} \mathrm{O}_{5}$ e $\mathrm{K}=0 \mathrm{~kg} / \mathrm{ha} /$ ano de $\mathrm{K}_{2} \mathrm{O}$ (Figura 2). Para essa mesma progênie o mínimo $\left(1,2 \mathrm{~g} / \mathrm{dm}^{3}\right)$ foi obtido com $\mathrm{N}=50$ a $350, \mathrm{P}=80$ a 150 e $\mathrm{K}=200$.

A densidade radicular máxima estimada para a progênie 2 foi de $6,10 \mathrm{~g} / \mathrm{dm}^{3}$, obtida com $\mathrm{N}=400, \mathrm{P}=0$ a 200 e $\mathrm{K}=$ 200 (Figura 3). Para essa mesma progênie, o valor mínimo foi de $3,8 \mathrm{~g} / \mathrm{dm}^{3}$, para a seguinte combinação de elementos: $\mathrm{N}$ $=100$ a $150, \mathrm{P}=200$ e $\mathrm{K}=200$.

Para a progênie 3 , a densidade radicular máxima foi de $8,2 \mathrm{~g} / \mathrm{dm}^{3}$, obtida através da seguinte combinação: $\mathrm{N}$ $=400, \mathrm{P}=50$ a 100 e $\mathrm{K}=200$ (Figura 4). A densidade mínima de $4,6 \mathrm{~g} / \mathrm{dm}^{3}$ foi obtida em duas combinações diferentes: $\mathrm{N}=200$ a $280, \mathrm{P}=0$ e $\mathrm{K}=0$, ou $\mathrm{N}=100$ a $150, \mathrm{P}=200$ e $\mathrm{K}=200$.

Diferenças nutricionais observadas entre genótipos, tais como as aqui reportadas, são esperadas, visto que os processos de absorção, transporte e utilização de nutrientes estão sob controle genético (Baligar \& Fageria, 1997). Segundo Baligar e Bennett (1986), a densidade radicular e a morfologia das raízes afetam especialmente a eficiência de absorção de potássio e fósforo, pela maior ou menor interceptação das rotas de difusão.

Embora com diferenças marcantes entre as progênies, a maior densidade radicular esteve sempre relacionada à doses elevadas de nitrogênio $(400 \mathrm{~kg}$ / ha/ano de N). No entanto, em plantas onde o produto comercial é constituído pelo conjunto de folhas, como a pupunheira para palmito, ênfase deve ser dada aos fatores que promovam também o crescimento da parte aérea. Torna-se, portanto, imperativo verificar se essa maior densidade radicular, alcançada com doses balanceadas de nitrogênio, fósforo e potássio, se reflete em maior biomassa aérea.

\section{LITERATURA CITADA}

ANILKUMAR, K.S.; WAHID, P.A. Root activity pattern of coconut palm. Oléagineux, v. 43, n. 8-9, p. 337 - 342, 1988.

AVILAN, L.; RIVAS, M.; SUCRE, R. Estudio del sistema radical del cocotero. Oléagineux, v. 39, n. 1, p. 13 - 23, 1984.

BALIGAR, V.C.; BENNETT, O.L. Outlook on fertilizer use efficiency in the tropics. Fertilizer Research, v. 10, n. 4, p. 83 - 96, 1986.

BALIGAR, V.C.; FAGERIA, N.K. Nutrient use efficiency in acid soils: nutrient management and plant use efficiency. In: MONIZ, A.C. ed. Plant-soil interactions at low $\mathrm{pH}$. Campinas: Sociedade Brasileira de Ciência do Solo, 1997. p. $75-95$.

BARLEY, K.P. The configuration of the root system in relation to nutrient uptake. Advances in Agronomy, v. 22, n. 2, p. 159 - 201, 1970.

BÖHM, W. Methods of studying root systems. Berlin: Springer-Verlag, 1979. 189 p.

BONNEAU, X.; OCHS, R.; QUSAIRI, L.; LUBIS, L.N. Nutrition minérale des cocotiers hybrides sur tourbe de la pépinière à l'entrée en production. Oléagineux, v. 48, n. 1, p. 9 26, 1993.

BOVI, M.L.A. Palmito pupunha: informações básicas para cultivo. Campinas: Instituto Agronômico, 1998. 50 p. (Boletim Técnico 173).

BOVI, M.L.A; CANTARELLA, H. Pupunha para extração de palmito. In: RAIJ, B.; CANTARELlA, H.; GUAGGIO, J.A.; FURLANI, A.M.C. eds. Recomendações de adubação para algumas culturas do Estado de São Paulo. Campinas: Instituto Agronômico, 1996. p. 240 - 242. (Boletim Técnico 100).

BOVI, M.L.A.; BASSO, L.C.; TUCCI, M.L.S. Avaliação da atividade "in vivo" da fosfatase ácida em Bactris gasipaes cultivada em dois níveis de nitrogênio e fósforo. Revista Brasileira de Ciência do Solo, Viçosa, v. 22, n. 3, p. 427 - 434, 1998.

BUWALDA, J.C.; GOH, K.M. Host-fungus competition for carbon as a cause of growth depressions in vesicular-arbuscular mycorrhizal ryegrass. Soil Biology and Biochemistry, v. 14, n. 2, p. 103 - 106, 1982.

CHULAN, H.A. Effect of fertilizer and endomycorrhizal inoculum on growth and nutrient uptake of cocoa (Theobroma cacao L.) seedlings. Biology and Fertility of Soil, v. 11, n. 4, p. $250-254,1991$.
FARRELL, R.E.; WALLEY, F.L.; LUKEY, A.P.; GERMIDA, J.J. Manual and digital lineintercept methods of measuring root length: a comparison. Agronomy Journal, v. 85, n. 6, p. 1233 -1237, 1993.

FERREIRA, S.A.N.; CLEMENT, C.R.; RANZANI, G. Contribuição para o conhecimento do sistema radicular da pupunheira (Bactris gasipaes H.B.K. - Guilielma gasipaes (H.B.K.) Bailey) I - Solo Latossolo Amarelo, textura média. Acta Amazônica, Manaus, v. 10, n. 2, p. 245 - 249, 1980.

FERREIRA, S.A.N.; CLEMENT, C.R.; RANZANI, G.; COSTA, S.S. Contribuição ao conhecimento do sistema radicular da pupunheira (Bactris gasipaes Kunth, Palmae). II. Solo latossolo amarelo, textura argilosa. Acta Amazônica, Manaus, v. 25, n. 3-4, p. $161-170,1995$.

FUJIWARA, M.; KURACHI, S.A.H.; ARRUDA, F.B.; PIRES, R.C.M.; SAKAI, E. A técnica de estudo de raízes pelo método do trado. Campinas: Instituto Agronômico, 1994. 9 p. (Boletim Técnico 153).

GARDNER, W.R. Dynamic aspects of water availability. Soil Science, v. 89, n. 1, p. 63 73, 1960.

GROSS, K.L.; MARUCA, D.; PREGITZER, K.S. Seedling growth and root morphology of plants with different life-histories. New Phytologist, v. 120, n. 4, p. 535 - 542, 1992.

HARDON, J.J. Oil palm breeding - Introduction. In: CORLEY, R.H.V., HARDON, J.J.; WOOD, B.J. eds. Oil Palm Research. New York: Elsevier, 1982. p. 89 - 108.

HARTLEY, C.W.S. The oil palm (Elaeis guineensis Jacq.), 2 ed. London: Longman, Tropical Agriculture Series, 1977. 806 p.

HAUSER, S. Root distribution of Dacryladenia (Acioa) barteri and Senna (Cassia) siamea in alley cropping on Ultisol. I. Implication for field experimentation. Agroforestry Systems, v. 24, n. 2, p. 111 - 121, 1993.

JORGE, J.A.; BOVI, M.L.A. Influência das propriedades físicas e químicas do solo no crescimento da palmeira pupunha. In: CONGRESSO BRASILEIRO DE FRUTICULTURA 13., 1994, Salvador. Resumos expandidos. Salvador: SBF, 1994. p. 1145 - 1146.

MENGEL, K. Responses of various crop species and cultivars to fertilizer application. Plant and Soil, v. 72, n. 2-3, p. 305 - 319, 1983.

MORA-URPÍ, J. El pejibaye (Bactris gasipaes H.B.K.): origen, biología floral y manejo agronómico. In: MORA-URPÍ ed. Palmeras poco utilizadas de América Tropical. Turrialba: Food and Agriculture Organization y Centro Agronómico Tropical de Investigación y Enseñanza (CATIE), 1984. p.118 - 160.

MORA-URPÍ, J.; CLEMENT, C.R. Races and populations of peach palm found in the Amazon basin. In: CLEMENT, C.R.; CORADIN, L. eds. Peach palm (Bactris gasipaes H.B.K.) germplasm bank. Manaus: US-AID project report, Manaus, 1988. p. 78 94. (Final report revised)

MORA-URPÍ, J.; WEBER, J.C.; CLEMENT, C.R. Peach palm. Bactris gasipaes Kunth. Promoting the conservation and use of underutilized and neglected crops. 20. Rome: Institute of Plant Genetics and Crop Plant Research, Gaterleben and International Plant Genetic Resources Institute, 1997. 83 p. 
MORALES, A.L.; VARGAS, H.S. Observaciones sobre la distribucion radical del pejibaye (Bactris gasipaes H.B.K.) para palmito en un andosol. ASBANA, v. 14, n. 34 , p. 9 - 15, 1990.

MULLINS, G.L.; REEVES, D.W.; BURMESTER, C.H.; BRYANT, H.H. In-row subsoiling and potassium placement effects on root growth and potassium content of cotton. Agronomy Journal, v. 86, n. 1, p. 136 - 139, 1994.

OLLAGNIER, M.; OCHS, R. Management of mineral nutrition in industrial oil palm plantation. Fertilizers savings. Oléagineux, v. 36, n. 4, p. 539 - 544, 1980 .

PACHÊCO, R.G. Crescimento de mudas de pupunha (Bactris gasipaes H.B.K.) em resposta à calagem e às relações cálcio/magnésio do solo e em resposta às relações nitrato/amônio e alumínio em soluções nutritivas. Viçosa: UFV, 1997. 102 p. (Tese doutorado).

PAVAN, M.A. Efeito da adubação mineral na distribuição do sistema radicular da macieira. Revista Brasileira de Ciência do Solo, Campinas, v. 19, n. 3, p. 477 - 480, 1995.
PENG, S.; EISSENSTAT, D.M.; GRAHAM, J.H.; WILLIAMS, K.; HODGE, N.C. Growth depression in mycorrhizal citrus at highphosphorus supply. Plant Physiology, v. 101, n. 4, p. 1063 - 1071, 1993.

RUER, P. Morphologie et anatomie du système radiculaire du palmier à huile. Oléagineux, v. 22, n. 10, p. 595 - 599, 1967a.

RUER, P. Répartition en surface du système radiculaire du palmier à huile. Oléagineux, v. 22, n. 9, p. 535 - 537, 1967 b.

SALISBURY, F.B.; ROSS, C.W. Plant physiology. 4 ed. Belmont: Wadsworth Publishing Company, 1991. 682 p.

SIEVERDING, E. Vesicular-arbuscular mycorrhiza management in tropical agrosystems. Eschborn: Technical Cooperation, 1991. 371 p.

SUDO, A.; SILVA, E.M.R.; BOVI, M.L.A; ALMEIDA, D.L.; COZZOLINO,K. Produção de mudas de pupunheira colonizadas por fungos micorrízicos arbusculares. Revista Brasileira de Ciência do Solo, Campinas, v. 20, n. 4, p. 529 - 532, 1996.
TAILLIEZ, B. Le système racinaire du palmier a huile sur la plantation de San Alberto (Colombie). Oléagineux, v. 26, n. 10, p. 435 447, 1971.

TAMPUBOLON, F.H.; DANIEL, C.; OCHS, R Réponses du palmier à huile aux fumures azotées et phosphorées à Sumatra. Oléagineux, v. 45, n. 11, p. 475 - 484, 1990.

TINKER, P.B. Soil requirements of the oil palm. In: CORLEY, R.H.V., HARDON, J.J.; WOOD, B.J. eds. Oil Palm Research. New York: Elsevier, 1982. p. 165 - 181.

TOMLINSON, P.B. The structural biology of palms. Oxford: Clarendon Press, 1990. 463 p.

VANDERMEER, J. Observations on the root system of the Pejibaye palm (Bactris gasipaes H.B.K.) in Costa Rica. Turrialba, v. 27, n. 3, p. $239-242,1977$. 